\title{
Progesterone and oestradiol-17 $\beta$ concentration profiles throughout the reproductive cycle in harbour seals (Phoca vitulina)
}

\author{
P. J. H. Reijnders \\ Research Institute for Nature Management, Dept. Estuarine Ecology, P.O. Box 59, \\ 1790 AB Den Burg, The Netherlands
}

\begin{abstract}
Summary. Serum samples of harbour seals kept in captivity were analysed for progesterone and oestradiol-17 $\beta$. The hormone profiles obtained were used to describe a complete reproductive cycle. A clear peak in oestradiol values, indicative of ovulation, was followed by elevated concentrations of progesterone. Implantation probably occurred 3-3.5 months thereafter. Progesterone concentrations rose significantly in the last 3-4 months of gestation, whereas oestradiol concentrations gradually increased after implantation. Lactational oestrus was marked by a peak of oestradiol on average 25 days after parturition and lactation lasted 4-5 weeks. Previous pregnancy had a marked influence on the timing of oestrus; females with offspring started a new reproductive cycle about 14 days later than previously non-pregnant seals. No differences in timing of parturition between the 2 groups were observed. This was probably the result of a flexible period of delayed implantation.
\end{abstract}

Keywords: harbour seal; progesterone; oestradiol

\section{Introduction}

Harbourseals, Phoca vitulina, exhibit a seasonal pattern of reproduction with annual and synchronous breeding cycles. Their reproductive pattern is characterized by an obligatory period of delayed implantation, i.e. embryonic diapause. The length of embryonic diapause and the duration of postimplantation gestation has been estimated by combining information on the presence or absence of both swelling of the uterine horns and fetuses in females with corpora lutea with data on embryonic growth rates (Fisher, 1954; Harrison, 1963; Bishop, 1968; Bigg, 1969; Bigg \& Fisher, 1974; Boulva $\&$ McLaren, 1979). These studies show that embryonic diapause lasts $2-3$ months and the average duration of fetal growth, estimated by using both prenatal growth rates and mean birth dates, lasts $8-8 \cdot 5$ months.

Reproductive biology of pinnipeds has predominantly been described in conjunction with behavioural observations and complemented by morphological data on reproductive organs (Laws, 1956; Harrison, 1960, 1963; Amoroso et al., 1965; Sinha \& Erikson, 1972; Bigg \& Fisher, 1974; Boshier, 1981). Some information on various reproductive events in pinnipeds has been published based on estimation of reproductive hormone concentrations (Daniel, 1974, 1975; Raeside \& Ronald, 1981; Boyd, 1983, 1984; Hobson \& Boyd, 1984). However, none of these studies reported hormonal changes during a complete annual reproductive cycle in a specific group of females and, although Reijnders (1986) presented some data for harbour seals in relation to some toxic effects of marine pollutants, the aim of the present study was to document changes in the serum concentration of oestradiol and progesterone in individual harbour seals throughout the reproductive cycle. This paper documents these changes in the same groups of seals as were used by Reijnders (1986) which involved feeding fish from a highly polluted area to one group and fish from a less 
polluted area to another. Although an effect of the treatment with fish containing high levels of pollutants was to reduce the reproductive rate of the treated group, comparison of hormone concentrations in both groups suggested there was no difference between the treated and untreated groups up to the time of implantation. Therefore, for the purpose of this paper, information about reproductive hormone concentrations up to implantation was combined from both groups.

\section{Materials and Methods}

Animals. The animals were captured as adults in The Wash, UK $(\mathrm{N}=14)$, or recruited from a breeding group in the Museum of Natural History (Ecomare) at Texel, The Netherlands $(\mathrm{N}=10)$. The animals from the Museum were born there from parents which came from the Wadden Sea. Since harbour seals can produce their first pup at the age of 4 years, some individuals were sexually immature when they were collected but all reached maturity in the course of the experiment. They were part of an experiment to test the impact of contaminated food on reproduction and were therefore equally divided in two groups of 12 females each. Details about the different diets of the two groups are described by Reijnders (1986). In addition a specially composed supplement (predominantly vitamins and thiamine hydrochloride) was regularly administered to both groups of seals. The seals were housed during the experimental period from 1981 to 1984 in two separate basins of $30 \times 6 \times 1.8 \mathrm{~m}$ each. These were supplied with running seawater at a rate of $50 \mathrm{~m}^{3}$ per hour. Alongside each basin, a concrete platform $(30 \times 3 \mathrm{~m})$ was constructed to allow the seals to haul-out. Apart from a few minor injuries due to aggressive encounters, the animals exhibited no health problems.

The number of participating animals is relatively small and a further subdivision in several categories only implicates even smaller sample sizes and the respective standard deviations become consequently rather large. Because of this and the fact that there was no effect of the difference in diet on concentrations of hormones or changes in concentration patterns of hormones in each group until the period of implantation (Wilcoxon $\alpha=0.05$; Spearman $\alpha=0.05$ respectively), the data from the treated group were used in Figs 1 and 2 with the data from the untreated group. A similar combination was used in Figs 3(b) and (c) but only for the period until implantation.

There was less information towards the end of gestation because we wished to avoid stressing the seals by sampling close to the time of parturition. Serum samples from 8 harbour seals at the Ecomare Museum were also obtained during this phase of the cycle to supplement samples collected at our institute. These animals received the same diet and the serum samples were analysed in the same run as those from the other seals.

Blood sampling. Blood samples were obtained from veins in the hindflippers when the animals were restrained on a $\mathrm{V}$-shape bench, modified after a device described by Ronald et al. (1969). The blood, about $10 \mathrm{ml}$, was taken at least once very month and more frequently during July, August, October and November (see Fig. 3). All animals in one group were sampled on the same day, the sampling always took place between 11:00 and 14:00 h local time and blood was collected in glass vacutainers. After centrifugation, the serum was stored frozen at $-20^{\circ} \mathrm{C}$.

Hormone estimations. Serum concentrations of oestradiol-17 $\beta$ and progesterone were determined by radioimmunoassay (RIA) according to the techniques described by Bouckaert (1984).

Oestradiol-17 $\beta$ was determined by RIA (Eidg. Institute for Nuclear Research, Würenlingen, Switzerland). There was $100 \%$ cross-reaction with oestradiol, $2 \%$ for oestrone and oestriol and $<0.1 \%$ for ethinyloestradiol, progesterone, testosterone and androstanediol. The inter- and intra-assay coefficients of variation were $9 \cdot 1 \%$ and consistently below $3.1 \%$ respectively; the limit of detection was $0.03 \mathrm{nmol} / \mathrm{l}$. Progesterone concentrations were determined by RIA (Farmos Diagnostica, Turku, Finland). The cross-reactivity was $100 \%$ for progesterone, $75 \%$ for $11 \beta$-hydroxyprogesterone, $8.8 \%$ for $5 \alpha$-dihydroxyprogesterone, $7.1 \%$ for $5 \beta$-dihydroxyprogesterone, $<0.3 \%$ for a number of hydroxyderivates of progesterone, and $0.9 \%$ for corticosteroids, testosterone and oestrogens. The cross-reaction of the antibody for $11 \beta$-hydroxyprogesterone is rather high. However, as it only occurs in the fmol/l concentration range it did not affect the interpretation of the progesterone concentrations. The inter- and intra-assay coefficients of variation were $8.3 \%$ and consistently below $3.0 \%$ respectively; the limit of detection was $0.28 \mathrm{nmol} / 1$.

\section{Results}

The follicular phase in the oestrous cycle in harbour seals is described on the basis of oestradiol-17 $\beta$ profiles (Fig. 1). The average time difference between parturition and the peak in oestradiol was 25.5 days ( $\pm 2 \cdot 5$ s.d.; $n=5$ ). If a concentration of $60 \mathrm{pmol} / 1$ is taken as a mean for non-ovulatory activity in mature females, derived from the period August-October, the average duration of the elevated oestradiol concentrations calculated in this way is 15 days ( \pm 3.5 s.d.; $n=7$ ). As the sampling was relatively infrequent, the actual period could have been shorter than 15 days. There were individual differences in timing of oestrus but, apart from this, there is also a difference in timing caused by the fact that lactating females will start a new reproductive cycle later than 
previously non-pregnant animals (Fig. 2). The average time difference between both categories, based on ovulatory peaks in oestradiol, was $14 \cdot 2$ days $( \pm 3.1$ s.d.). The difference in timing of oestrus between previously pregnant and previously non-pregnant animals was also found in the start of luteal activity indicated by an increase in serum progesterone concentrations. The average time difference was 14.9 days ( \pm 2.9 days s.d.), which is similar to the difference found using the ovulatory rise in oestradiol.
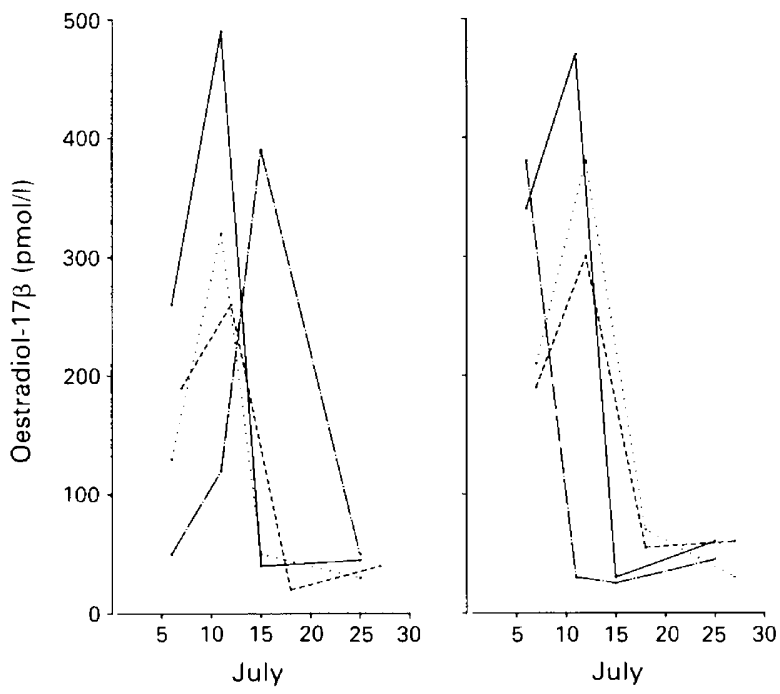

Fig. 1. Oestradiol-17 $\beta$ profiles in serum of 8 harbour seals (4 in each panel for reasons of clarity), during the follicular phase of oestrus. The first day of sampling was on 5 July (left) and 7 July (right).

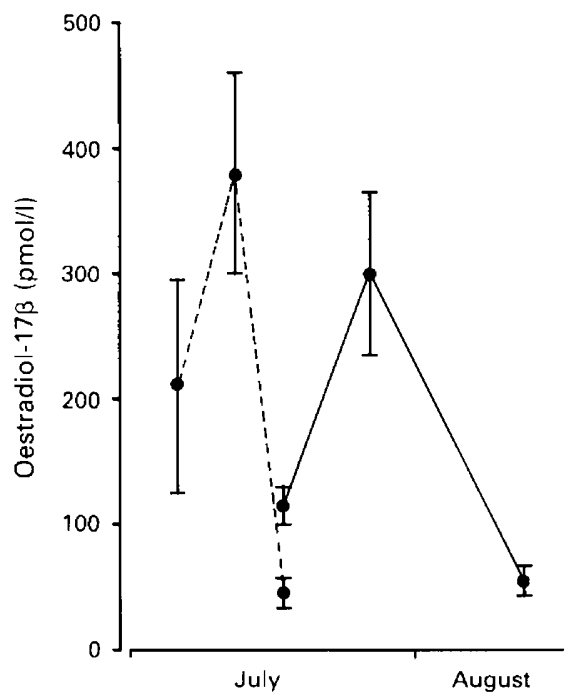

Fig. 2. Oestradiol-17ß profiles synchronized for previously pregnant $(-\quad-\quad \mathrm{N}=6)$ and non-pregnant $(\mathbf{0}---\mathbf{O} ; \mathrm{N}=10$ ) harbour seals. Vertical bars $=1$ s.d. 


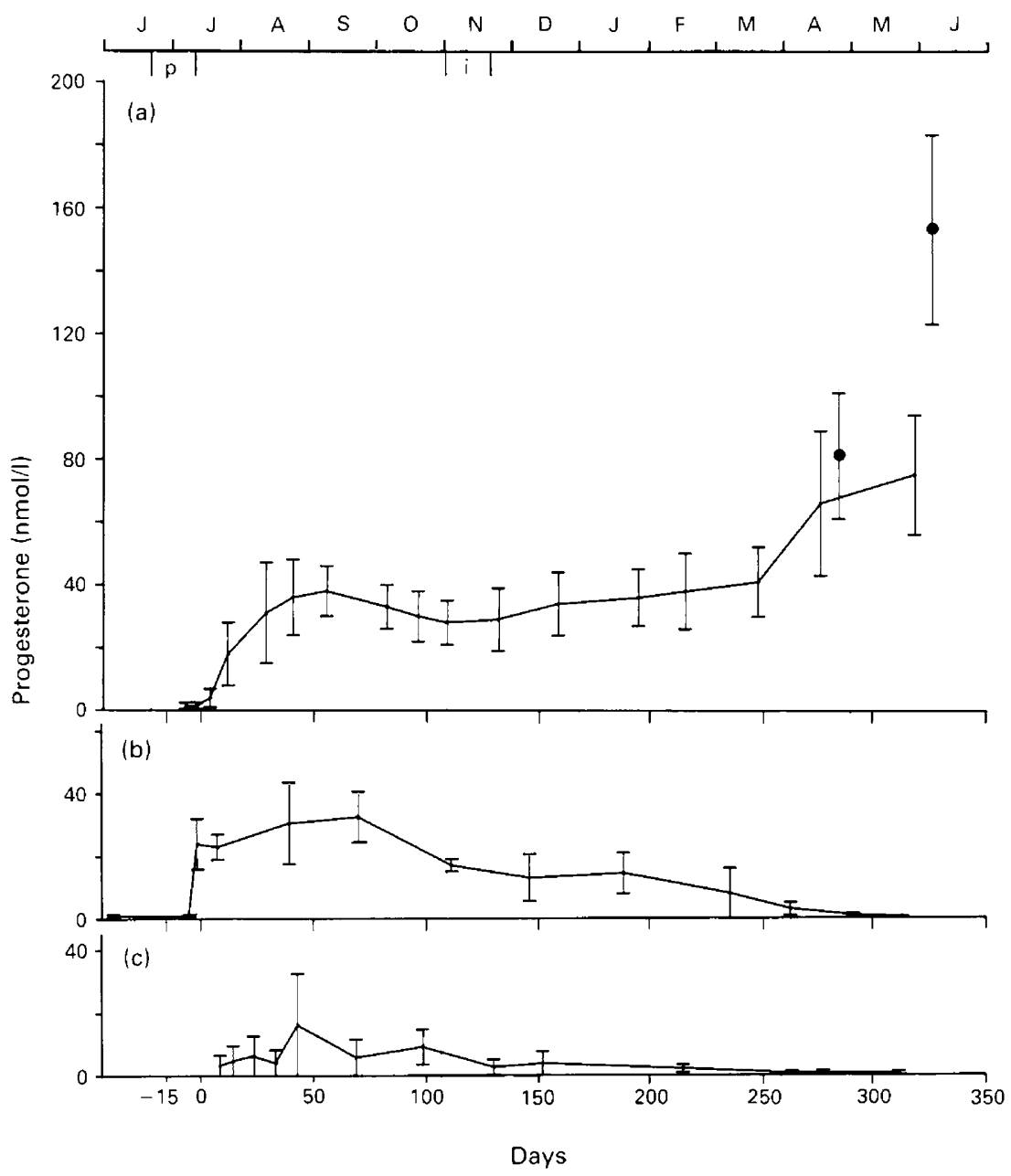

Fig. 3. Circulating serum concentrations of progesterone in harbour seals expressed as time (in days) relative to post-ovulatory rise in progesterone. The months of the year in which various events normally occur are given above the graph. (a) Pregnant seals $(\mathrm{N}=10)$; (b) non-pregnant mature seals $(\mathrm{N}=8$ until November, $\mathrm{N}=4$ thereafter); (c) immature seals $(\mathrm{N}=5)$ and mean of 8 animals from Ecomare $(\bullet)$. Vertical bars $=1$ s.d.; $p=$ period over which previous parturitions occurred; $\mathrm{i}=$ implantation period.

To describe a general pattern for a complete reproductive cycle, all hormone profiles, have to be synchronized in time. It was not possible to synchronize all by birth date as the groups consisted of previously pregnant and previously non-pregnant seals. Therefore, all cycles were synchronized by the timing of the post-ovulatory rise in progesterone. The data for the non-pregnant seals were collected in the year before the collection of the data for pregnant seals. The patterns of progesterone and oestradiol-17 3 for immature seals collected in the year before they matured (from the second half of July), are presented in Figs $3 \& 4$. No specific synchronization period was available for immature seals and therefore the data were plotted according to the actual time of sampling. In mature animals, elevated concentrations of oestradiol followed by elevated concentrations of progesterone in serum indicated that ovulation occurred. After the post-ovulatory rise in progesterone, sustained elevated concentrations and a subsequent increase towards the end of gestation of both hormones were found in the pregnant animals. The highest concentrations of progesterone were 


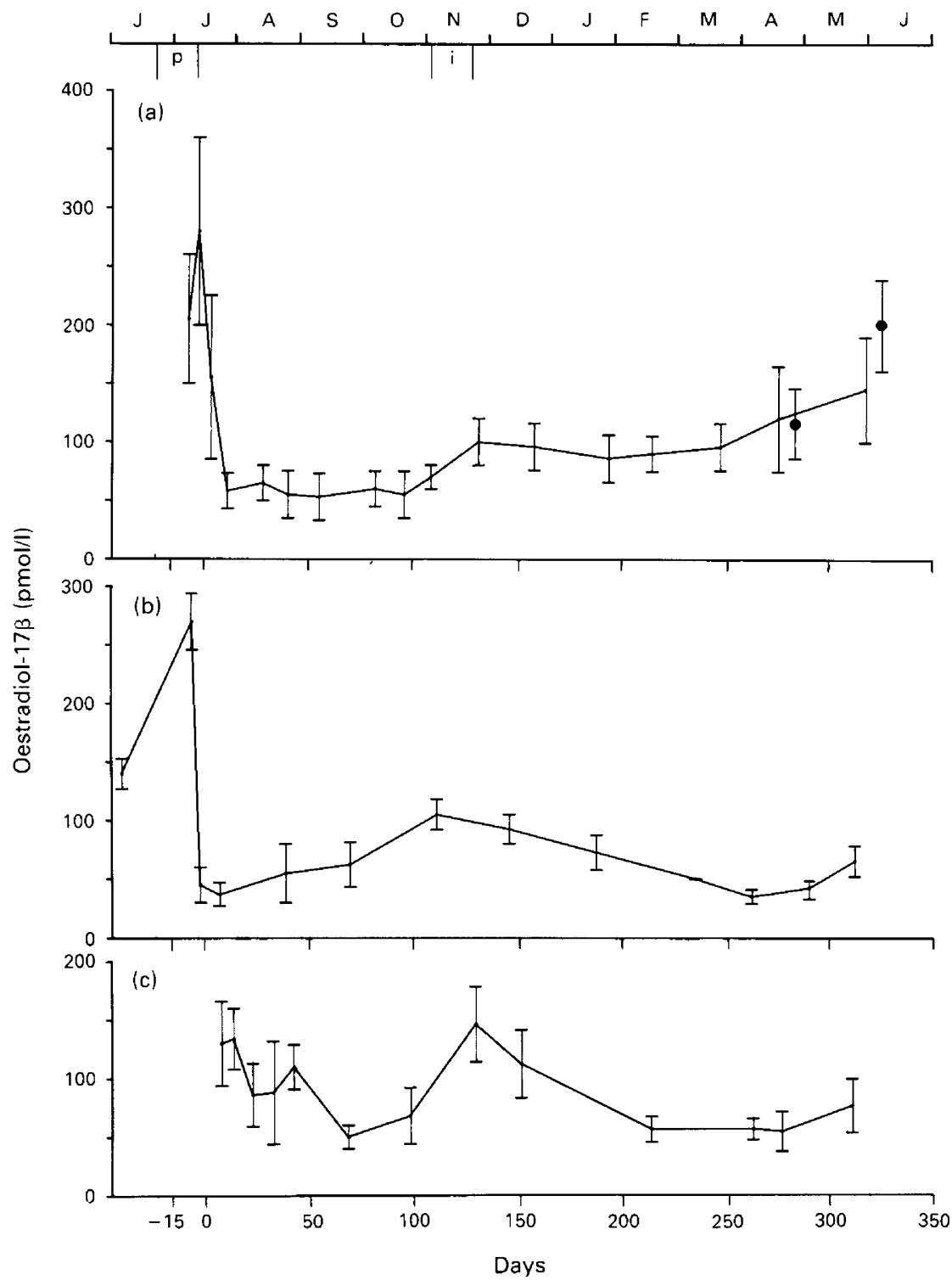

Fig. 4. Circulating serum concentrations of oestradiol-17 $\beta$ in harbour seals expressed as time (in days) relative to post-ovulatory rise in progesterone. The months of the year in which various events normally occur are given above the graph. (a) Pregnant seals $(\mathrm{N}=10)$; (b) nonpregnant mature seals $(\mathrm{N}=8$ until November, $\mathrm{N}=4$ thereafter); (c) immature seals $(\mathrm{N}=5)$ and mean of 8 animals from Ecomare (-). Vertical bars $=1$ s.d.; $p=$ period over which previous parturitions occurred; $\mathrm{i}=$ implantation period.

observed towards the end of gestation followed by a sharp decline at parturition. In this study progesterone and oestradiol only increased significantly in the last 3-4 months of gestation. Both observations are based on the significant differences between the mean of the values in March and May (Student's $t$ test, $P<0.05$ ) and the similar statistical difference found between the means of the samples from Ecomare during April and June.

There were marked differences between both the concentration of progesterone in mature seals compared with prepubertal seals but differences were not as great for oestradiol. The progesterone 
concentrations were lower in prepubertal seals (Fig. 3), whereas the concentration range for oestradiol was comparable and the profiles resembled those in mature seals except the ovulatory peak (Fig. 4).

\section{Discussion}

This study has demonstrated significant changes in the serum concentrations of progesterone and oestradiol during the annual reproductive cycle of female harbour seals, including significant differences between the cycles of immature, pregnant and non-pregnant individuals.

Maintenance of elevated progesterone concentrations and a subsequent increase towards the end of gestation was only found in pregnant females. This is similar to the findings of Boyd (1984) for grey seals and is almost certainly due to increased progesterone production from the placenta (Boyd, 1984; Hobson \& Boyd, 1984).

The luteal phase in non-pregnant females apparently lasted for 4-5 months after ovulation as reflected by progesterone secretion from the corpus luteum for some time before regressing. This could be interpreted as pseudopregnancy and is of an equivalent duration to the delay of implantation in pregnant females, as was also found by Bigg \& Fisher (1974).

The first major differences in oestradiol concentrations between pregnant and non-pregnant seals appear after implantation. Sustained elevated concentrations and a subsequent increase towards the end of gestation are only found in pregnant seals. This was also observed in the same species by Raeside \& Ronald (1981) and in grey seals by Boyd (1982).

Serum oestradiol concentrations increased within 3 weeks after parturition while lactation continued for at least a further week. This phenomenon of lactational oestrus is found in many species of seals (Laws, 1956; Craig, 1964; Burns, 1970; Øritsland, 1975; Boness \& James, 1979; Stewart \& Lavigne 1980; Gentry, 1981; Boyd, 1983).

Pinnipeds are classified as having an obligate and seasonal embryonic diapause (Renfree \& Calaby, 1981). This delayed implantation is a universal feature in pinnipeds (Harrison, 1963; Boshier, 1981), but considerable differences are found when comparing eared seals (Otariidae) and true seals (Phocidae) with respect to their physiological control of diapause and implantation. In harbour seals progesterone concentrations remained elevated throughout embryonic diapause, as was also found in grey seals (Boyd, 1984), but in northern fur seals progesterone concentrations were low during lactation, remained low throughout embryonic diapause and then increased at implantation (Daniel, 1974, 1975).

The exact length of embryonic diapause in harbour seals is not very well known, but the duration of post-implantation gestation is relatively constant (Laws, 1956; Boshier, 1981). Therefore, it is assumed that implantation in harbour seals in this study occurred between the end of October and the 3 rd week of November. This is supported by the observation that serum concentrations of oestradiol increased at that time in the cycle, as was also found in grey seals (Boyd, 1982). However, a surge in oestradiol concentrations as was found in the northern fur seal (Daniel, 1974) was not detected in this study or in an earlier study of grey seals (Boyd, 1982). This could possibly have been because the blood sampling regimen in this study was not frequent enough to detect a short-term increase in oestradiol. However, as most cycles are not synchronous and no high value was detected in any seal, it is concluded that a similar surge in oestradiol levels most likely did not occur. These differences in steroid hormone cycles between the northern fur seal and the harbour and grey seal could be explained by different courses of physiological evolution, as discussed by Boyd (1982).

However, the differences in the timing of oestrus were not subsequently reflected by differences in the respective parturition dates (Spearman $\alpha=0.05 ; n=9$ ). In addition, by using the rise in oestradiol as an indication of implantation and the patterns of progesterone in pregnant and nonpregnant animals around that period, the differences in timing of implantation are subsequently 
reflected by the differences in the timing of parturitions (Spearman $\alpha=0 \cdot 05 ; n=10$ ). It therefore is concluded that the timing of parturition is probably determined by the timing of implantation.

The pronounced annual changes in oestradiol-17 $\beta$ concentrations of immature seals may be a consequence of folliculogenesis. Craig (1964) found a profound annual cyclicity of follicular activity in the ovaries of nulliparous northern fur seals which supports this explanation.

I thank the staff of the Sea Mammal Research Unit (Cambridge, UK) and colleagues from my institute for valuable help in collecting the seals in The Wash; Theo Vleugel for animal care; Jaap Klinkers for veterinary care; Koos Zegers for assistance throughout the whole experiment; and Arno Gijzen, Harry Janssens and Guido van Weert for the RIAs and support and cooperation.

\section{References}

Amoroso, E.C., Bourne, G.H., Harrison, R.J., Matthews, L.H., Rowlands, I.W. \& Sloper, J.C. (1965) Reproductive and endocrine organs of foetal, new born and adult seals. J. Zool., Lond. 147, 430-486.

Bigg, M.A. (1969) The harbour seal in British Columbia. Bull. Fish. Res. Bd Can. 172, 33 pp.

Bigg, M.A. \& Fisher, H.D. (1974) The reproductive cycle of the female harbour seal off Southeastern Vancouver Island. In Functional Anatomy of Marine Animals, Vol. 2, pp. 329-347. Ed. R.J. Harrison, Academic Press, London.

Bishop, R.H. (1968) Reproduction, age determination, and behaviour of the harbour seal, Phoca vitulina $L$., in the Gulf of Alaska. M.Sc. thesis, University of Alaska, College. Alaska, $121 \mathrm{pp}$.

Boness, D.J. \& James, H. (1979) Reproductive behaviour of the Grey seal (Halichoerus grypus) on Sable Island, Nova Scotia. J. Zool., Lond. 188, 477-599.

Boshier, D.P. (1981) Structural changes in the corpus luteum and endometrium of seals before implantation. J. Reprod. Fert., Suppl. 29, 143-149.

Bouckaert, P.X.J.M. (1984) Peritoneum liquid: biochemical changes during the menstrual cycle. Thesis, University of Nijmegen, Netherlands, $156 \mathrm{pp}$. [In Dutch, with English summary.]

Boulva, J. \& McLaren, I.A. (1979) Biology of the Harbour Seal, Phoca vitulina, in Eastern Canada. Bull. Fish. Res. Bd Can. 200, 24 pp.

Boyd, I.L. (1982) Reproduction of Grey seals with reference to factors influencing fertility. Ph.D. thesis, University of Cambridge, $168 \mathrm{pp}$.

Boyd, I.L. (I983) Luteal regression, follicle growth and the concentration of some plasma steroids during lactation in grey seals (Halichoerus grypus). J. Reprod. Fert. 69, 157-164.

Boyd, I.L. (1984) The relationship between body condition and the timing of implantation in pregnant grey seals (Halichoerus grypus). J. Zool., Lond. 203, 113-123.

Burns, J.J. (1970) Remarks on the distribution and natural history of pagophilic pinnipeds in the Bering and Chukchi Seas. J. Mammal. 51, 445-454.

Craig, A.M. (1964) Histology of reproduction and the oestrus cycle in the female fur seal, Callorhinus ursinus. J. Fish. Res Bd Can. 21, 773-811.

Daniel, J.C. (1974) Circulating levels of oestradiol-17 $\beta$ during early pregnancy in the Alaskan fur seal showing an oestrogen surge preceding implantation. $J$. Reprod. Fert. 37, 425-428.
Daniel, J.C. (1975) Concentrations of circulating progesterone during early pregnancy in the northern fur seal Callorhinus ursinus. J. Fish. Res. Bd Can. 21, $773-811$.

Fisher, H.D. (1954) Delayed implantation in the harbour seal, Phoca vitulina. Nature, Lond. 173, 979-980.

Gentry, R.L. (1981) Northern fur seal-Callorhinus ursinus. In Handbook of Marine Mammals, Vol. 1, pp. 143-160. Eds S. H. Ridgway \& R. J. Harrison. Academic Press, London.

Harrison, R.J. (1960) Reproduction and reproductive organs in common seals (Phoca vitulina) in the Wash, East Anglia. Mammalia 24, 372-385.

Harrison, R.J. (1963) A comparison of factors involved in delayed implantation in badgers and seals in Great Britain. In Delayed Implantation, pp. 99-114. Ed. A. C. Enders. University of Chicago Press, Chicago.

Hobson, B.M. \& Boyd, I.L. (1984) Gonadotrophin and progesterone concentrations in placentae of grey seals (Halichoerus grypus). J. Reprod. Fert. 72, 521-528.

Laws, R.M. (1956) The elephant seal (Mirounga leonina Linn.) 3. The physiology of reproduction. Falk. Is. Dep. Serv. Sci. Rep. 15, 1-74.

Oritsland, T. (1975) Sexual maturity and reproductive performance of female hooded seals at Newfoundland. ICNAF Research Bulletin 11, 37-41.

Raeside, J.I. \& Ronald, K. (1981) Plasma concentrations of oestrone, progesterone and corticosteroids during late pregnancy and after parturition in the harbour seal, Phoca vitulina. J. Reprod. Fert. 61, 135-139.

Reijnders, P.J.H. (1986) Reproductive failure in common seals feeding on fish from polluted coastal waters. Nature, Lond. 324, 456-457.

Renfree, M.B. \& Calaby, J.H. (1981) Background to delayed implantation and embryonic diapause. $J$. Reprod. Fert., Suppl. 29, 1-9.

Ronald, K., Foster, M.E. \& Johnson, E. (1969) The harp seal, Phoca groenlandica (Erxleben, 1777). Physical blood properties. Can. J. Zool. 47, 461-468.

Sinha, A.A. \& Erickson, A.W. (1972) Ultrastructure of the corpus luteum of Antarctic seals during pregnancy. Z. Zellforsch. mikrosk. Anat. 117, 35-45.

Stewart, R.E.A. \& Lavigne, D.M. (1980) Neonatal growth of northwest Atlantic harp seals, Pagophilus groenlandicus. J. Mammal. 61, 670-680.

\section{Received 3 January 1990}

